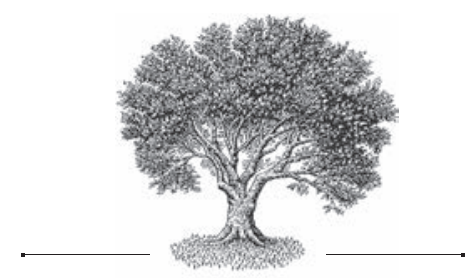

\title{
Наталя Яковенко,
}

У пошуках Нового неба. Життя і тексти Йоаникія Галятовського

Київ: Лаурус, Критика, 2017. 704 с., библ., илл.

\author{
Маргарита Анатольевна Корзо \\ Институт философии РАН \\ Москва, Россия
}

\author{
Margarita A. Korzo \\ Institute of Philosophy, \\ Russian Academy of Sciences \\ Moscow, Russia
}

Новую книгу известного украинского историка Натальи Яковенко можно по праву назвать событием: через призму сочинений духовного писателя и богослова киево-могилянского круга Иоанникия Галятовского (ум. 1688) анализируются не только его идеи и представления - то, что составляло интеллектуальную "кухню” мыслителя, но и ставятся более масштабные проблемы формирования особого интеллектуального пространства в Киевской митрополии XVII в. и специфики религиозной культуры Украины раннего Нового времени.

Иоанникий Галятовский выбран в качестве главного персонажа не случайно: он был одним из самых плодовитых и читаемых православных авторов второй половины XVII в. Все его сочинения, над которыми он трудился между 16591687 гг., вышли из печати еще при его жизни и получили распространение далеко за пределами Киевской митрополии. Будучи ярким представителем киевского духовенства, он был, одновременно с этим, и по уровню образования, и по кругу своих интеллектуальных интересов и религиозных исканий совершенно типичным представителем своей эпохи. А потому в нем как в зеркале можно и увидеть, и попытаться эту эпоху лучше понять.

Книга состоит из предисловия, шести разделов, озаглавленных цитатами из сочинений Галятовского, послесловия, библиографии, списка иллюстраций, указателей и двух приложений: перечень ссылок в украиноязычных сочинениях Галятовского и сведения об авторах, упомянутых или процитированных Галятовским. 
Характеристике жизненного пути и особенностям интеллектуального становления Иоанникия Галятовского, написанных им сочинений, а также их читателям, пользователям и собирателям посвящен первый раздел книги (“Виждь смиренїє моє и труд мой”).

Раздел второй (“Розныє книги для написаня моєй книги читаючи”) анализирует библиотечный ресурс Галятовского (где он мог получить доступ к книгам? что читал, и от чего зависели его читательские предпочтения?), что становится поводом для автора остановиться на характеристике книжных собраний Киевской митрополии (частновладельческих, монастырских, церковных братств, др.) и их региональной специфики; зафиксировать феномен использования православными авторами книжного ресурса школьных и монастырских библиотек отдельных католических орденов (с. 105). Значительная часть раздела отведена анализу техник чтения Галятовского и многоступенчатости его работы над отдельными трудами, когда прежние выписки постепенно обрастали новыми фактами и аргументами, призванными усилить достоверность того или иного примера (c. 113). Через изменение ссылочного аппарата в различных изданиях одного и того же сочинения исследуется проблема их переадресации: так, исчезновение во втором издании “Ключа разумения” (Львов, 1663) ссылок на античных авторов, образующих канон чтения школьного курса риторики той эпохи, свидетельствует, по мнению Н. Яковенко, об обращенности его в бо́льшей степени к неискушенному в школьной мудрости духовенству. И эти выводы подтверждаются материалами визитаций, фиксирующими преобладание именно этой версии “Ключа разумения" в приходских библиотеках (с. 100-101).

Автор книги фиксирует уникальный даже для литературной ситуации Киевской митрополии той эпохи пример виртуозного владения Галятовским на письме одновременно несколькими “речевыми регистрами”: от разговорной речи до тяжеловесной фразеологии из арсенала неосхоластики. Выбор всегда определялся коммуникативной ситуацией, зависел от “собеседника” Галятовского в том или ином сочинении. Н. Яковенко расшифровывает значение высказываний своего персонажа через привязку его речи к определенной социальной или культурной среде, в которой данные языковые конструкции использовались.

Самой популярной части наследия Галятовского - проповедническим текстам - отводится третий раздел книги (“Запрошаю ласк ваших до слуханя”). Автор выражает несогласие с бытующим в литературе тезисом о появлении проповедничества лишь в 1570-1580 гг., ссылаясь на факты (хотя и не очень многочисленные) более раннего бытования на землях Киевской митрополии рукописных Учительных Евангелий (с. 204-205). XVII в. принес появление нового - западного по своему происхождению типа гомилетики, хотя и эти “новые проповеди” не смогли до конца вытеснить из церковного обихода традиционные Учительные Евангелия (с. 207). Особенностью Киевской митрополии второй половины XVII в. было сосуществование приверженцев святоотеческого типа проповеди (например, Лазарь Баранович) и приверженцев новой, основанной на активном использовании “концептов”, гомилетики, к которым относился и Галятовский. В книге анализируются его “техники общения” с аудиторией (с. 227-230), система стилистических эффектов проповедей Галятовского (с. 231-233). Н. Яковенко ставит также вопрос об оригинальности гомилетического пособия своего персонажа 
“Наука албо способ зложеня казаня” (1659), усматривая авторское начало Галятовского лишь в тех метафорических “подобенствах”, с помощью которых он объяснял в своих проповедях нюансы вероучения (с. 219-227).

В четвертом разделе (“Богословове наши научают”) выявляются элементы заимствования из католического вероучения в сочинениях Галятовского на примере избранных сюжетов (понимание сущности и последствий первородного греха, время преосуществления Святых Даров, Непорочное зачатие Девы Марии, эсхатология), церковных обрядов, иконописных образцов и отдельных богословских терминов. Предваряя каждый из сюжетов небольшим историческим экскурсом, Н. Яковенко стремится показать, в чем Галятовский был новатором, а в чем - следовал уже существующим в Киевской митрополии практикам. К безусловным заслугам Галятовского автор относит попытку в трактате “Мессия правдивый” перевести формулы схоластического богословия и выработать научный дискурс на украинском языке (с. 280). Данный опыт долго оставался уникальным, поскольку богословские курсы читались в Могилянском коллегиуме на латинском языке.

В пятом разделе (“Святыє суть приятелями нашими”) рассматриваются представления о святости и культе святых в Киевской митрополии, их эволюция на протяжении XVII в., особенности богородичного культа и его трансформация под влиянием латинских образцов марийной духовности, фиксируется появление нового для православного дискурса акцента в понимании “совершенного христианина” и перенесение акцентов с монахов-пустынников на активных исповедников веры. Одной из принципиальных новаций Галятовского Н. Яковенко считает использование exempla с латинскими святыми, обращение к которым преследует надконфессиональные дидактические цели, отражает пастырское стремление способствовать “оживлению веры” верующих (с. 392). Сопоставляя агиографический проект своего персонажа с чуть более поздними усилиями Димитрия Ростовского, Н. Яковенко констатирует, что замысел Галятовского по освоению католического сакрального пространства не имел продолжения и отражал скорее всего его личную позицию, но не “более широкие тенденции религиозной культуры киевских церковных интеллектуалов” второй половины XVII столетия (с. 391).

Шестой и последний раздел книги (“3 своим дишкурсом скрийся, Жидовине, под лаву”) отведен анализу отношения к евреем на примере первого православного антииудейского трактата “Месїя правдивый” (1669). Отказавшись от анализа теологической системы аргументации Галятовского, автор сосредоточила свое внимание на социальном фоне, который вызвал к жизни данное сочинение, на арсенале антииудейской полемики и его зависимости от более ранних западных образцов, на используемых в трактате нарративных приемах. Отдельное внимание Н. Яковенко уделяет “рецептам” Галятовского по решению “еврейской проблемы”, прагматизм которых выдает их западное происхождение: они варьируют от принудительной конфискации материальных ценностей и использования их на “социальные нужды”, стимулирования обращения в христианство до сепарации еврейского и христианского населения, разрушения синагог, запрета на проживание в пределах государства (с. 493-497).

Отдельного внимания заслуживает справочный аппарат книги, включающий помимо библиографии, списка иллюстраций и подробного указателя еще и 
полную расшифровку в виде таблицы всех ссылок и цитат из проанализированных в монографии украиноязычных сочинений Галятовского (с. 597-684). Впечатляет масштаб проделанной Н. Яковенко работы, которая сама признается, что ссылки ее героя порой не только лаконичны до неузнаваемости, но также изобилуют опечатками и курьезными ошибками, которые, хотя и служили благодатным материалом для изучения техник чтения Галятовского, серьезно затрудняли работу по их дешифровке. С другой стороны, значительное сокращение в примечаниях названий цитируемых латинских сочинений могло свидетельствовать о том, что Галятовский говорил со своим читателем на общем для них языке, что читатель был в состоянии сам расшифровать эти ребусы, а следовательно, был с этими сочинениями хорошо знаком (с. 114-115).

Корпус использованных Галятовским памятников состоит из 320 печатных книг: его библиотечный ресурс включает преимущественно латинских авторов и латиноязычные издания Отцов Церкви, дополняется девятью богослужебными книгами, а также информацией, почерпнутой из устных свидетельств. Богословская аргументация черпается из трудов Августина (на первом месте по числу цитирований), за которым следуют иезуит Корнелий а Лапиде и Иоанн Златоуст; “Annales Ecclesiastici” ораторианца Цезаря Барония (1538-1607) и энциклопедический по своему характеру труд Теодора Цвингера (1533-1588) “Theatrum humanae vitae” используются как источники разного рода exempla; фундаментальный труд картезианца Лаврентия Сурия (1522-1578) “De probatis sanctorum historiis” стал одним из источников знакомства Галятовского с византийской агиографией. За реконструкцией корпуса латинских памятников стоит более серьезная проблема, к которой Н. Яковенко неоднократно обращается на протяжении всей книги: может ли такой библиотечный ресурс что-то сказать исследователю и о процессе мышления Галятовского? По каким критериям происходит отбор текстов и информации, как она сортируется и “препарируется” (редактируется/сокращается/расширяется) для использования в процессе создания собственного текста? За всем этим стоит и понимание того, каким образом происходило распространение знания в религиозной книжности Киевской митрополии (или его “перетекание” из латинской традиции, по меткому выражению автора книги), в какой степени эти процессы на киевской почве воспроизводили западные модели второй половины XVI в. эпохи господства громоздких компендиумов универсального знания обо всём (с. 13).

Анализ библиотечного ресурса Галятовского позволил Н. Яковенко аргументированно проговорить ряд положений, которые до этого хотя и встречались в единичных исследованиях, но исключительно в форме слабо артикулированных интуиций. К подобного рода положениям относится, в частности, тезис о польском интеллектуальном доминировании на протяжении всего XVII в. Н. Яковенко корректирует данный тезис, считая его актуальным лишь для первой половины XVII столетия, когда именно польская книга была одним из основных источников эрудиции для православных авторов Киевской митрополии. Второе поколение могилянцев, к которому принадлежал и Иоанникий Галятовский, обращается уже напрямую к западной (= латиноязычной) печатной продукции, которая становится доминирующей частью интеллектуального ландшафта православных авторов. Это не означает, что польскоязычная литература ими не читалась и не использовалась, но означает, что она утратила функцию основного посредника и транслятора 
знания (богословского, агиографического, исторического, др.). Эту идею автор акцентированно проговаривает во “Введении” (с. 11-12) и в рассуждениях о характере использования “Великого Зерцала примеров” в сочинениях Галятовского (c. 137), но также подтверждает ее на протяжении всей книги, анализируя источники сочинений своего главного персонажа ${ }^{1}$.

Доминирование латинского книжного ресурса с неизбежностью ставит вопрос о том, чем была для православных авторов Киевской митрополии латинская традиция; как в текстах и в головах носителей “киевской учености” второй половины XVII в. уживались сформированные задолго до этой эпохи каноны религиозного мышления с новациями, почерпнутыми из западных изданий и практик; вопрос о содержании и статусе заимствований из католического богословия, агиографии и иконографии.

Открытость к латинской традиции не означала “всеядности” могилянцев. Эрудит Галятовский был очень избирателен в своем чтении: в широко используемых им латинских exempla он видел в первую очередь то, что соответствовало его личному нравственному опыту и этосу православного монаха (с. 169). Отношение к латинской традиции проявляется и в стратегиях цитирования Галятовского, который в отдельных случаях параллельно со ссылкой на западного автора (богослова, агиографа, церковного историка) приводит отсылку на византийского хрониста, раннехристианского автора или греческого богослова, чтобы уравновесить “латинское” свидетельство “греческим”. Похожим образом поступает Галятовский и с отдельными exempla, дополняя латинское свидетельство информацией из Пролога или “Измарагда”, что усиливает эффект достоверности выбранного примера и делает его более узнаваемым для православного читателя $(\text { c. 174) })^{2}$. Использовал Галятовский, как считает Н. Яковенко, и ряд неотрефлексированных им самим приемов освоения “латинского материала”, что особенно заметно на примере редактирования Галятовским отдельных католических чудес, в которых остаются чудеса, но исчезают католики (с. 182).

Столь же избирательно поступает Галятовский, когда речь идет о заимствованиях из католического богословия. Это особенно заметно, когда он препарирует те латинские exempla и описания чудес, в которых проговариваются догматические различия католического и православного вероучений. Хотя далеко не всегда Галятовский проделывает данную процедуру с одинаковой степенью строгости: он более последователен, например, в избегании упоминаний о чистилище и гораздо менее последователен, когда речь идет о Непорочном зачатии Богородицы (с. 182-183).

На примере целого ряда сюжетов (понимание сущности и последствий первородного греха, время преосуществления Святых Даров во время причастия, Непорочное зачатие Девы Марии, эсхатология), церковных обрядов, иконописных

1 Отчасти схожие тенденции (хотя и в значительно более скромном масштабе) были отмечены Л. И. Сазоновой и для русского литературного процесса второй половины XVII в.

2 Аналогичный метод “подтверждения восточных источников западными авторами” и наоборот был присущ и другим писателям могилянского круга: Н. Яковенко ссылается на наблюдения Дж. Броджи Беркофф над проповедническим наследием Антония Радивиловского (1620-1688) [Brogi Bercoff 2012: 414-424]. 
образцов и отдельных богословских терминов Н. Яковенко демонстрирует, что заимствования из латинской традиции проникают гораздо раньше и являются в эпоху Галятовского уже некой не ставящейся под сомнение данностью. Эта данность подвергается сознательной рефлексии лишь тогда, когда извне зазвучали упреки в “неправославности” богословских построений киевских книжников, примером чему могут послужить московские дискуссии конца XVII столетия вокруг так наз. “хлебопоклоннической ереси”. Конфессиональная открытость Киевской митрополии формировалась стихийно, еще с середины XVI в. (в сфере обрядности, культа святых, отдельных иконографических канонов и т. д.) просто в силу близкого культурного соседства двух христианских традиций, приводившего к “перемешиванию” верований, церковных обрядов и практик. Могилянская же эпоха придала этой открытости некоторое завершенное каноническое оформление (с. 10).

В книге показано, что отдельные черты религиозной культуры Киевской митрополии, которые считаются в литературе проявлениями сознательной латинизации православия, могли быть вызваны к жизни иными причинами. Так, нарастающая в первой трети XVII в. тенденция фиксировать чудеса по западной модели (с верификацией обстоятельств чуда и привлечением достоверных свидетельств) и численный рост задействованных в этих чудесах мирян были вызваны не столько процессами латинизации и заимствования, сколько распадом Киевский митрополии после Брестской церковной унии на две части. Этот распад ставил и перед православными, и перед униатами задачу продемонстрировать бо́льшую благодатность своей церкви; и не последнюю роль в этом подтверждении играли чудеса. Латинская же модель “презентации чуда” оказалась очень подходящей в данном противостоянии и была взята за образец в первую очередь по прагматическим, нежели по иным соображениям.

Тезис о прагматизме отдельных латинских заимствований в религиозной культуре и богословской мысли Киевской митрополии уже встречался в литературе [Korzo 2002; Melnyk, Pilipowicz 2003: 45; Thomson 1993: 98, 101], что не снимает насущности проблемы продумывания последствий этих заимствований как для мировоззрения отдельного верующего, так и культуры в целом. Пример Галятовского демонстрирует, сколь парадоксально в одном человеке могли сочетаться, например, православный эсхатологический оптимизм (когда чудеса-награды численно доминируют над чудесами-наказаниями) и при этом понимание греха и спасения в категориях католического вероучения; притом что последнее выражалось словесно с использованием понятий православного богословия (с. 266268). Галятовский мог одновременно “думать” в присущих латинской традиции категориях чистилища и частного суда, но описывать соответствующие процедуры с помощью вполне себе православного понятия “мытарства”.

Подобное сочетание несочетаемого (названное Л. Бережной “барочной логикой” Галятовского [Бережна 2005: 267]) было присуще могилянцам и не свидетельствует об утрате ими православной идентичности. Они не преследовали цели разрушить византийскую матрицу вероучения - они стремились лишь подвести под православное мировоззрение новую теоретическую базу и этим укрепить свою экклезиологическую идентичность. Христианский опыт воспринимался могилянцами как универсальный, чему совершенно не противоречило их полемическое противостояние с католиками по целому ряду богословских и обрядовых 
моментов. Своей книгой Н. Яковенко не только наглядно показывает данный парадокс могилянца-Галятовского, который постоянно демонстрировал свою “греческость”, хотя зачастую “думал на латыни”, но и призывает заново “перечитать” всю православную культуру Киевской митрополии переломного XVII в., чтобы лучше понять ее усилия по поиску своей идентичности как своеобразного третьего пути - между католицизмом и православием (с. 500).

\section{Библиограсрия}

Бережна 2005

Бережна Л., “«Третіе мъсто удержаніе истяжательное». Ідея митарств у творах Йоаникія Галятовського та українських православних синодиках”, in: Л. Довга, Н. Яковенко, ред., Україна XVII століття: суспільство, філософія, культура, Київ, 2005, 267-280.

Brogi Bercoff 2012

Brogi Bercoff G., “The Sermons of Antoniy Radyvylovs'kyj: History, Culture, Mentality,” in: Н. Білоус, Л. Довга, В. Михайловский, Н. Старченко, М. Яременко, ред., Theatrum humanae vitae. Студіï на пошану Наталі Яковенко, Київ, 2012, 414-424.

Korzo 2002

Korzo M., "Prawosławne wyznanie wiary Piotra Mohyły. Kilka uwag w sprawie wpływów zachodnich na teologię kijowską XVI w.," Odrodzenie i Reformacja w Polsce, 46, 2002, 141-149.

Melnyk, Pilipowicz 2003 Melnyk M., Pilipowicz W., Kazania i komentarze sakramentalno-liturgiczne z "Trebnika" św. Piotra Mohyty, Olsztyn, 2003.

Thomson 1993

Thomson F. J., "Peter Mogila's Ecclesiastical Reforms and the Ukrainian Contribution to Russian Culture. A Critique of Georges Florovsky's Theory of the Pseudomorphosis of Orthodoxy," Slavica Gandensia, 20, 1993, 71-114.

\section{References}

Berezhnaya L., “«Tretie mesto uderzhanie ystiazhatelnoe». Ideia mytarstv u tvorakh Yoanykiia Galiatovskoho ta ukraïnskykh pravoslavnykh synodykakh," in: L. Dovha, N. Yakovenko, eds., Ukraïna XVII stolittia: suspilstvo, filosofiia, kultura, Kyï, 2005, 267-280.

Brogi Bercoff G., "The Sermons of Antoniy Radyvylovs'kyj: History, Culture, Mentality,” in: N. Bilous, L. Dovga, V. Mykhailovsky, N. Starchenko, M. Yaremenko, eds., Theatrum humanae vitae. Studia in honorem Natali Jakovenko, Kyï, 2012, 414-424.
Korzo M., "Prawosławne wyznanie wiary Piotra Mohyły. Kilka uwag w sprawie wpływów zachodnich na teologię kijowską XVI w.," Odrodzenie i Reformacja $w$ Polsce, 46, 2002, 141-149.

Melnyk M., Pilipowicz W., Kazania i komentarze sakramentalno-liturgiczne z "Trebnika" św. Piotra Mohyty, Olsztyn, 2003.

Thomson F. J., "Peter Mogila's Ecclesiastical Reforms and the Ukrainian Contribution to Russian Culture. A Critique of Georges Florovsky's Theory of the Pseudomorphosis of Orthodoxy," Slavica Gandensia, 20, 1993, 71-114.

Маргарита Анатодьевна Корзо, канд. ист. наук

Институт философии РАН, старший научный сотрудник сектора этики 109240 Москва, ул. Гончарная, д. 12, стр. 1

Россия/Russia

korzor@zmail.ru 